\title{
Satanismo e inversão de valores em "O réu Tadeu”, de Eça de Queirós
}

\author{
Silvio Cesar dos Santos Alves ${ }^{1}$
}

\begin{abstract}
RESUMO: Neste artigo pretendemos alcançar dois objetivos complementares: abordar o satanismo em "O réu Tadeu" - novela incompleta de Eça de Queirós que foi publicada primeiramente em julho de 1867, no Distrito de Évora, e recolhida postumamente nas Prosas esquecidas, em 1965; e comparar esse satanismo com a inversão de valores pregada por Nietzsche em sua obra.
\end{abstract}

ABSTRACT: This article is intended to achieve two complementary objectives: to address the satanism in "O réu Tadeu" - unfinished story of Eça de Queirós, first published in July 1867, in the Distrito de Évora, and collected posthumously in Prosas esquecidas, in 1965; and to compare this satanism with the inversion of values preached by Nietzsche in his work.

PALAVRAS-CHAVE: Satanismo; Inversão de valores; Niilismo.

KEYWORDS: Satanism; Inversion of values; Nihilism.

No "Prólogo" de Humano, demasiado humano, Nietzsche afirma não acreditar "que alguém, alguma vez, tenha olhado para o mundo com mais profunda suspeita, e não apenas como eventual advogado do Diabo, mas também, falando teologicamente, como inimigo e acusador de Deus" (NIETZSCHE, 2005, p. 7). Sabemos que há muita retórica nessa afirmação, mas em que medida Nietzsche realmente teria sido um "advogado do Diabo" e um "inimigo e acusador de Deus"? Em termos filosóficos, como "inimigo e acusador de Deus", Nietzsche combatera a visão moral fundadora do cristianismo, que ele chamava de "platonismo do povo"; e, como "advogado do Diabo", não só aceitou a necessidade do "Mal", como, também, pretendeu ver a sua beleza.

A relação proposta por Nietzsche entre platonismo e cristianismo baseia-se na hierarquia que essas duas doutrinas estabelecem entre a superioridade de um mundo considerado "verdadeiro" e a inferioridade de um mundo visto como "falso". Ao empreender sua crítica à noção de verdade orientada pela metafísica e pela moral tradicionais, Nietzsche parece pretender uma inversão do platonismo, e, portanto, do cristianismo. Entretanto, no tomo I de Nietzsche, Martin Heidegger afirma que a "inversão" nietzschiana "e, com ela, a interpretação do verdadeiro como o que é dado sensivelmente precisam ser compreendidas a partir da superação do niilismo" (HEIDEGGER, 2007a, p. 146).

Em Crepúsculo dos ídolos, no sexto tópico da "História de um erro", em que apresenta a "história do niilismo" como a história da inserção e da retirada de valores na cultura ocidental, Nietzsche pergunta se com a abolição do "mundo verdadeiro" teria restado o "aparente". Mas ele logo responde que "Com o mundo verdadeiro abolimos

\footnotetext{
${ }^{1}$ Doutorando em Literatura Comparada (UERJ). Pesquisa: Os paradoxos do niilismo em Antero de Quental, Cesário Verde e Eça de Queirós. Email: silviohaiti@hotmail.com.
} 
também o mundo aparente" (NIETZSCHE, 2006, p. 32). Essa conclusão aponta para uma complexidade que ultrapassa a simples inversão da hierarquia estabelecida entre os antigos valores. Sobre essa complexa noção de "inversão", Heidegger é bastante elucidativo ao afirmar que

Nem a supressão do sensível nem a do não_-sensível são necessárias. Ao contrário, o importante é afastar as falsas interpretações e a diabolização do sensível, assim como a superestimação do suprassensível. O importante é liberar o caminho para uma nova interpretação do sensível a partir de uma nova hierarquização do sensível e do não-_sensível (HEIDEGGER, 2007a, p.186).

Em Nietzsche e a verdade, Roberto Machado argumenta que se "a superação do niilismo é a postura radical que significa dizer um sim dionisíaco a tudo o que foi negado, desvalorizado até então, mostrando que todo esse outro lado não apenas é necessário, mas até mesmo desejável”, e se a crítica nietzschiana "diz respeito a todos os valores prevalentes, uma das saídas que justamente se ofereciam a Nietzsche era inverter a hierarquia de valores instaurada pelo niilismo como modo de escapar da desvalorização que ele representa". Porém, denunciar "a moral como imoral, o bem como mal, o verdadeiro como falso", e "virar de cabeça para baixo todos os valores", considerando "Deus uma pura e simples invenção, uma astúcia do diabo" diz respeito a apenas um dos aspectos da transvaloração nietzschiana, a um momento apenas inicial desse processo (MACHADO, 2002, passim 87-8). Segundo Machado,

Quando Nietzsche se propõe a valorizar os valores que foram historicamente negados pelo niilismo não é apenas, nem fundamentalmente, para mudar os valores de lugar, para substituir os valores e portanto conservar o lugar. Tirar os valores morais do lugar de valores supremos, que dominam e dão sentido a todos os valores, só será possível destruindo este lugar que foi instituído pela própria moral. O que implica necessariamente mudar o elemento de onde se originam os valores, o princípio de avaliação, a própria maneira de ser de quem avalia (MACHADO, 2002, p. 88).

A especulação sobre a legitimidade do "Mal" num século cada vez mais esvaziado dos signos que representavam uma ordem fundada em sua contenção ou justificação, como foi o século XIX, não foi apenas objeto das reflexões filosóficas de Nietzsche. No universo literário oitocentista, essas questões foram abordadas antecipadamente em relação à própria filosofia. Os chamados "poetas do mal" foram os primeiros advogados do Diabo, inimigos e acusadores de um Deus ausente, testemunhas 
da penúria. O satanismo desses poetas representou uma consciente atitude de revolta contra o "velho mundo" divinamente orientado, ao afirmar o mal de forma voluptuosa, desafiando a moral estabelecida e profanando símbolos religiosos. A idealização do amor, a crença na bondade humana e no progresso também foram alvos atacados por essa tendência poética que apenas via em Deus o criador do mundo para acusá-lo através de sua própria criação. O poeta invocava o Diabo num desafio a Deus e à sociedade. Esse Diabo podia representar o próprio poeta, quando este se colocava numa perspectiva de superioridade em relação à sociedade, aos seus valores, à sua religião, ao sofrimento humano. O que não quer dizer que, em outras vezes, este ser desprezado por Deus, decaído de suas antigas insígnias na ordem celeste, não se compadecesse do homem em suas angústias, em suas incertezas e solidão no mundo. Mas, mesmo a figura de Satã, na medida em que sua "existência" sustentava-se pela própria metafísica cristã, também se tornaria alvo da blague dos que insurgiam contra os valores caducos. A partir da lição de Baudelaire, que empreendera uma verdadeira desromantização do romantismo, a poética satânica oscilaria entre um pessimismo frio, expurgado de toda a melancolia romântica, e um voluptuoso comprazimento com o mal. Ainda que tenha permanecido presa aos limites da metafísica cristã, à qual Nietzsche buscara ultrapassar com sua própria metafísica da vontade de poder, do eterno retorno do mesmo e da transvaloração, a literatura satânica, ao especular sobre a legitimidade ao mal através de seus processos estéticos, operou, ao seu modo, uma tentativa de inversão de valores muito próxima à que seria proposta por esse filósofo.

É nesse sentido que queremos chamar a atenção para um folhetim publicado pelo então jovem escritor português Eça de Queirós, em julho 1867, no Distrito de Évora. Trata-se de uma novela incompleta, composta de duas partes e que gira em torno da ocorrência de um suposto assassinato. Na primeira parte, menciona-se a prisão do personagem Tadeu Esteves, encontrado na casa em que morava, junto a um armário onde estava o cadáver de seu irmão Simão, como saberemos depois, morto enforcado. Durante o processo a que é submetido, Tadeu limita-se a confessar-se culpado. Vem a ser condenado à morte, por enforcamento. Enquanto aguarda a pena, passa os dias escrevendo de forma quase enlouquecida. No dia anterior à pena capital, recusa o padre, dizendo-lhe que tinha "motivos bastantes para amar Jesus", somente o fazia "em espírito" (QUEIRÓS, 1965, p. 43). Na última noite, escreve carta a uma Jerónima dizendo lembrar-se sempre dela. O narrador menciona, então, a "Paixão" que o teria traído, como Judas a Jesus. No outro dia, após subir à forca e ajeitar a corda ao próprio 
pescoço, Tadeu é executado.

Não há muitos detalhes a respeito do suposto crime ou de suas possíveis causas nessa primeira parte. Apenas ficamos sabendo, através de testemunhas, que o irmão de Tadeu havia se casado há um mês e que os três moravam juntos. Alguns dias antes da morte de Simão, sua mulher havia saído de casa. O mesmo ocorrera com Tadeu. Simão teria ficado só, deprimido, "amarelo como uma cera", tendo sempre "os olhos avermelhados de chorar" (QUEIRÓS, 1965, p. 39). À noite, de sua casa, ouvia-se "umas árias tão tristes que pareciam lamentações". Rompida a madrugada, ele "tomava o caminho da cidade, e só voltava ao escurecer": "Resultava daquelas declarações que aquela pobre alma sofria, que o mal entrara ali, levando as qualidades da noite - a obscuridade, o silêncio, o medo e a tristeza; mas não havia uma ideia justa do crime" (QUEIRÓS, 1965, p. 40).

$\mathrm{Na}$ segunda parte, porém, esboça-se o trio fatal que teria precedido ao suposto triângulo amoroso. A partir de uns papéis de Tadeu, o narrador revela a "história desordenada e convulsiva dos anos distantes que [este] passara, pobremente, com Simão". Simão "trabalhava na Escola de Medicina", enquanto Tadeu era "um contemplativo inútil" que "tocava rabeca e tinha o plano de compor uma sinfonia, intitulada 'Ofélia"” (QUEIRÓS, 1965, p. 46). Os dois tinham um amigo chamado Stanislau. Segundo Tadeu, ele lembrava o Satã de Ary Scheffer e "tocava rabeca com aquela convulsão nervosa com que nas legendas o Diabo toca bandolin" (QUEIRÓS, 1965, p. 48). Tadeu também dizia que ele e Stanislau representavam a Arte e a Alma, enquanto Simão era o representante da Família e o Trabalho (QUEIRÓS, 1965, p. 47).

É nessa segunda parte que conhecemos os discursos de Stanislau. Segundo o que Tadeu revela desse personagem em seus papéis, para ele toda a vida era um logro; o amor de mãe era "a especulação com a gratidão futura do filho"; o amor do filho era "um servilismo fingido para tornar menos pesado o encargo do pai” (QUEIRÓS, 1965, p. 50). Quanto ao amor da mulher, ele afirmava o seguinte: "nos primeiros dias, o amor da mulher é um amor-reconhecimento por quem lhe dá o prazer material, e, nos seguintes, uma captação de confiança para alcançar a liberdade do vício" (QUEIRÓS, 1965, p. 50). Dizendo-se preocupado com Simão, que acreditava na família, no casamento e na mulher, Stanislau tece uma série de considerações que, por um lado, oscilam do anticristianismo à misoginia, mas, por outro, parecem pôr em questão o próprio ponto de vista a partir do qual elas são enunciadas. Vejamos, por exemplo, o que ele diz sobre o papel da mulher no casamento: “É um combate. De um lado está a 
família, com o trabalho, a maternidade, a pureza, os encantos dos filhos, o dever, a justiça, a religião, o amor, Deus; elas estão sós do outro, e esmagam tudo isso" (QUEIRÓS, 1965, p. 50). Numa coincidência, o narrador encerra a seção em que esse discurso é enunciado com o seguinte fecho: “Assim falava Stanislau”. Em Assim falou Zaratustra, no episódio intitulado "Entre as filhas do deserto", o andarilho, "que se denominava a sombra de Zaratustra", toma a harpa do feiticeiro e põe-se a cantar uma canção em que exalta os prazeres dos sentidos. Num determinado trecho dessa canção ele diz: "[...] venho da Europa,/Que é mais cética do que todas as mulheres casadas" (NIETZSCHE, 2011, p. 292).

Noutro trecho do seu discurso, Stanislau faz um incitamento ao "vício", propondo que se erga "a hóstia do Mal" e que se busque, "se for necessário", o "sangue" "às veias dos nossos irmãos": "Decerto, sigamos a natureza. Deixemos caminhar as paixões” (QUEIRÓS, 1965, p. 53). O trecho a seguir merece ser reproduzido:

\footnotetext{
Que importa que aquele homem assassinasse o marido daquela mulher? Ela ama-o, quere-o assim coberto com um sangue que têm os seus filhos; respeite-se a paixão: que seja pois desse homem. Se desejares a mulher de teu irmão, toma-a para ti. Se apeteceres o pão de teu pai, deixa-o morrer à fome. Respeita a paixão que prostitui tua irmã. Respeita a natureza como um vestido; quem o despedaça, fere-o. Aceita a carne. Jesus, que era todo alma, considerava-a tanto que a deu em troca do céu. A carne é alguma coisa tão magnífica que encobria Deus aos místicos. Jesus não se fez aceitar senão tomando-a para pretexto da sua alma. Ama o que ela desejar. Serás feliz, porque a carne nunca quer as penas dos outros. E a alma nos seus desejos aceita todos os encargos, até as lágrimas (QUEIRÓS, 1965, p. 53).
}

Mencionávamos o andarilho que, em Assim falou Zaratustra, toma a harpa do feiticeiro e põe-se a cantar uma canção capaz de inflamar os sentidos. Queremos chamar a atenção agora para o feiticeiro. Esse personagem, no "Canto da melancolia", após a saída de Zaratustra, tenta fazer os seus ouvintes "caírem inadvertidamente, como pássaros, na rede de sua astuciosa e melancólica volúpia”. De sua harpa ele tira uma canção saudosa das antigas consolações, em que se recorda de uma vez em que estivera sedento "de lágrimas celestes". Em resposta aos que o acusam de "pretendente da Verdade", ele diz:

Não! Apenas poeta!

Um bicho ardiloso, de rapina, insinuante,

Que tem de mentir,

Que ciente, voluntariamente tem de mentir,

Ávido de presa, 


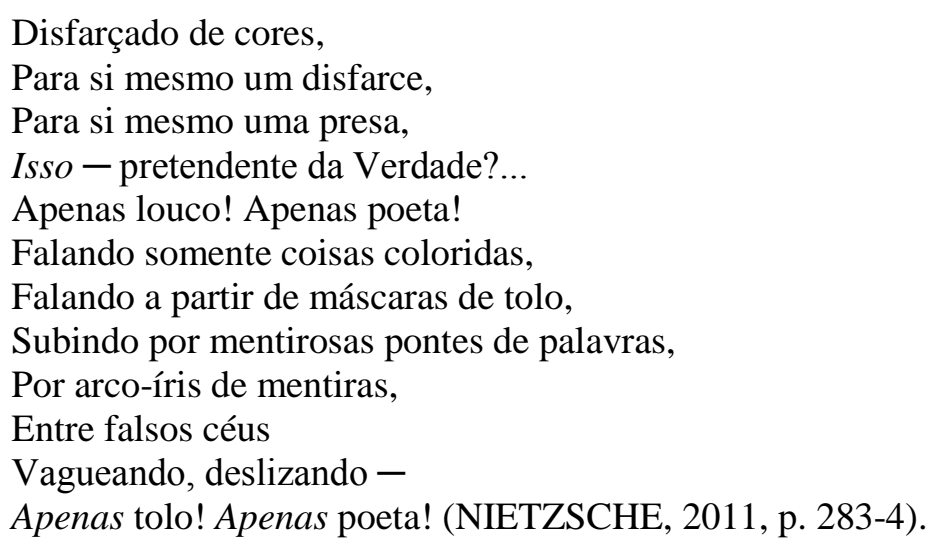

Esse feiticeiro, misto de louco e de poeta, dizia-se assaltado por um "maligno espírito de engano e sortilégio", o "melancólico demônio" contra o qual ele em vão lutava. Esse demônio, embora fosse "um adversário extremo" de Zaratustra, afeiçoavase, como ele, a todos os que sofriam do "grande nojo", a todos aqueles para os quais "o velho Deus [havia morrido] e nenhum novo Deus se [achava] envolto em faixas num berço". Por isso, para o feiticeiro, Zaratustra seria "uma bela máscara de santo", "um novo e estranho disfarce" com o qual o seu "mau espírito, o demônio melancólico", se comprazia. E era parecia-lhe ser este o motivo de seu amor por Zaratustra (NIETZSCHE, 2011, p. 282). Palavras de louco, palavras de poeta, nas quais não se pode fazer distinção entre mentira e verdade. Em suas memórias, Tadeu compara Stanislau a um "Diabo", mas a resposta que ele dá a si mesmo para se consolar acerca das palavras diabólicas do amigo dá-nos a entender que, para ele, em vez de "uma bela máscara de santo", Stanislau devia ser um santo disfarçado de demônio, de satanista incitador do "vício" e do "crime":

Talvez assim como os histriões põem vermelhão na face para esconder o seu medo, ele, para esconder a preguiça, a indolência, a pobreza, a animosidade pelo trabalho, tingia a alma de sangue.

Como não tinham a energia da pureza e da liberdade, refugiava-se na revolta. Queria viver pela luta e pelo desespero, por não ter a coragem e a força de viver pela família, pelo trabalho e pelo estudo!

Tinha um oculto amor por Jesus e pela legenda cristã; no entanto, dava à alma toda a sorte de atitudes ímpias e escarnecedoras (QUEIRÓS, 1965, p. 54).

Em Assim falou Zaratustra, uma mesma harpa serve tanto ao feiticeiro quanto ao andarilho. A harpa não tem moral, não tem religião, não tem culpa. Ela apenas soa, independente da mão que a toca, seja um demônio disfarçado de santo, seja um santo mascarado de demônio. Que rosto estaria escondido por trás da máscara representada pelas memórias de Tadeu? A visão final que ele nos dá de Stanislau representa uma 
tentativa de racionalização de tudo quanto há de irracional nas especulações que este faz sobre os valores tradicionais de Simão. Assim, a pena do jovem Eça apresenta-se, nessa breve e incompleta narrativa, como aquela harpa do feiticeiro e entrega-se de bom grado tanto ao réquiem de Stanislau, quanto ao hino de Tadeu, se é que ficamos sabendo quem foi este, ou aquele.

Em O primeiro Fradique Mendes, ao apontar a antecipação embrionária de aspectos fundamentais da novelística e do romance queirosianos já em "O réu Tadeu", sobretudo a partir da relação que essa obra estabelece entre o "Bem" e o "Mal", Joel Serrão chama-nos a atenção para o fato de que "aquilo que acaso aí ocorre de mais fundo respeita mediatamente às encruzilhadas do pensamento europeu ocidental que um Nietzsche, nascido, aliás, um ano antes de Eça de Queirós, traria à superfície nas suas fulgurações geniais" (SERRÃO, 1985, p. 129). Serrão, porém, argumenta que "não se está a sugerir que as vivências culturais portuguesas sintonizavam, ou sequer podiam sintonizar, com as inquietações filosóficas mais estruturadas e estruturantes da metafísica de além-Pirenéus", mas que "é lícito imaginar-se, em termos de história cultural e das mentalidades, que há ondas de fundo - ideias, vivências, atitudes -, e que algumas delas se espraiaram até à finisterra portuguesa". Segundo esse autor, "por isso é que a geração de 1865 pudera irromper, como tal, por entre os fragores e os anúncios e os prenúncios de uma derrocada geral de valores tradicionais, os quais, em última instância, eram os mesmos ídolos tombados ou a tombar um pouco por toda a Europa" (SERRÃO, 1985, p. 129-130). O que Serrão sugere é a ocorrência de um sincronismo e de uma atopia no que diz respeito ao surgimento dos efeitos intelectuais da crise de valores resultante do que Nietzsche chamara de a "morte de Deus". Essa hipótese encontra apoio nesta tese apresentada por Ulrich Weisstein, em Literatura comparada: definição:

[...] dentro de uma única civilização é possível encontrar-se elementos comuns de uma tradição, consciente ou inconscientemente mantidos em pensamento, emoção e imaginação, que podem, nos casos de uma emergência razoavelmente simultânea, ser vistos como tendências comuns significativas, e que, mesmo para além dos limites do tempo e do espaço, frequentemente constituem espantosos laços de unidade (WEISSTEIN, 1994, p. 312).

Pensamos que há deveras algumas "tendências comuns significativas" entre Eça de Queirós e Friedrich Nietzsche e que estas se constituem a partir de tentativas conscientes de inversão dos valores tradicionais, decorrentes da precursora percepção 
que esses autores tiveram de sua irreversível depreciação. Quanto aos "condicionalismos culturais e mentais" que teriam rolado lentamente até à "finisterra portuguesa", propiciando a existência, "para além dos limites do tempo e do espaço", de "espantosos laços de unidade" entre pontos importantes das obras de Eça e de Nietzsche - como tentamos demonstrar nesta análise de "O réu Tadeu" -, é possível supor que a obra do poeta alemão Heinrich Heine - cuja influência sobre Eça foi comprovada de modo categórico por Maria Manuela Gouveia Delille, em sua obra A recepção literária de H. Heine no romantismo português (de 1844 a 1871) - tenha sido uma espécie de canal por onde possivelmente teriam escoado influências temáticas e estilísticas entre o criador de Stanislau e o criador de Zaratustra.

Segundo Delille, nessa incompleta narrativa do jovem Eça, "exploram-se até as últimas consequências os pressupostos satânicos e faz-se - aliás com manifesta intenção de sátira aos valores morais burgueses - a justificação e sublimação do crime, a apologia do mal" (DELILLE, 1984, p. 348). O satanismo que se pode depreender de "O réu Tadeu" é mais que um romântico protesto contra as potestades divinas e parece constituir uma consciente tentativa de inversão de valores. Os valores deveriam ser invertidos porque se constatava que já não havia um sentido transcendente ao real circundante que os justificasse e garantisse sua correta observação. É assim que, numa das primeiras obras conhecidas de Eça, para mais além de um satanismo ainda romântico e recheado de Diabos lançadores de apóstrofes contra um Deus moribundo, de Diabos que também estavam em vias de dissolução, vemos o "Mal" perder o caráter metafísico com que a tradição e o romantismo o conceberam e aparecer, na visão de Stanislau, como alternativa a problemas socialmente condicionados, como, por exemplo, aqueles referentes à estrutura do casamento burguês.

Nessa breve e inconclusa novela, também já estão presentes duas antagônicas tendências que permaneceriam para sempre nos procedimentos estéticos queirosianos: um movimento no sentido de inverter ou derrubar os valores aceites na sociedade e outro no sentido de acusar a transgressão desses mesmos valores. Mas, o que mais chama a atenção nessa narrativa é que nela não encontramos o autor em parte alguma. Falamos daquilo que as escolhas relativas ao estatuto e à perspectiva do narrador podem revelar a respeito do posicionamento ideológico do autor. Essa relação não se dá de forma inequívoca em "O réu Tadeu”. Na primeira parte dessa obra, temos um narrador heterodiegético com uma perspectiva bastante limitada. Os principais fatos que nos são revelados são conhecidos de fora, apresentados de forma um tanto precária e reticente. 
Na segunda parte, graças a papéis que teriam sido escritos por Tadeu, a sua história nos é revelada através de uma comprometida narrativa homodiegética. Portanto, nenhuma leitura é segura, nenhuma interpretação e nenhum julgamento são garantidos ou subsidiados de antemão nessa narrativa. Temos uma obra verdadeiramente aberta. Talvez, para garantir que ela assim permanecesse, após a publicação da segunda parte, em Évora, Eça retorna a Lisboa, deixando-a para sempre inconclusa. Por isso, ela parece-nos o prólogo de uma longa história autoral que seria marcada por hesitações, recuos e silêncios. Em 1900, o epílogo dessa história dava-se quase nos mesmos termos de "O réu Tadeu": o autor ia-se para sempre e deixava sua obra, ou suas obras, sem conclusão, abertas também para sempre.

Referências bibliográficas:

DELILLE, Maria Manuela Gouveia. A recepção literária de H. Heine no romantismo português (De 1844 a 1871). Lisboa: Imprensa Nacional-Casa da Moeda, 1984.

HEIDEGGER, Martin. Nietzsche. Rio de Janeiro: Forense Universitária, 2007. Vol, I. MACHADO, Roberto. Nietzsche e a verdade. Rio de Janeiro: Graal, 2002.

NIETZSCHE, Friedrich Wilhelm. Assim falou Zaratustra. São Paulo: Companhia das letras, 2011.

. Crepúsculo dos ídolos. São Paulo: Companhia das letras, 2006.

. Humano, demasiado humano. São Paulo: Companhia das letras, 2005.

QUEIRÓS, Eça de. O réu Tadeu. In: Prosas esquecidas I: ficção 1866-72. Lisboa: Editorial Presença, 1965.

SERRÃO, Joel. O primeiro Fradique Mendes. Lisboa: Livros Horizonte, 1985.

WEISSTEIN, Ulrich. Literatura Comparada: Definição. In: COUTINHO, Eduardo; CARVALHAL, Tânia Franco (orgs.). Literatura Comparada: Textos fundadores. Rio de Janeiro: Rocco, 1994, p. 308-333. 